\title{
Governance of safety and security programs the use of nuclear technology in Indonesia
}

\begin{abstract}
In the framework of the 4.0 Industrial Era that focuses on technological advances in the present, nuclear technology for peaceful purposes by promoting safety and security of workers and the public and its environment becomes very important. In the use of nuclear technology, safety and security governance are important things to be aware of because expectations and reality are often not appropriate. The purpose of research is to formulate the governance of safety and security programs of the use of nuclear technology in Indonesia by understanding the interaction and contextual relationships 3 elements of purpose, constraints and institutional, and identifying sub-elements that have High power drivers and low dependence. It is necessary as an alternative material in the preparation of regulation and nuclear safety facing the Industrial Era 4.0. The method used is the Interpretive Structural Modeling (ISM) analysis. ISM analysis is intended to illustrate the structure of the nuclear technology safety and security governance Program. The research results of the key purpose elements are the safety assurance of workers, communities and the environment. To achieve these key objectives, elements of key constraints are weak in the implementation of occupational safety culture and have not been in fact dissemination of the implementation of nuclear technology in the general public. A key institutional element that is involved in the implementation of the safety and security management program of nuclear technology is the National Nuclear Energy Agency (BATAN). Data processing results of expert opinion is the consistency of $93-100 \%$.
\end{abstract}

Volume 6 Issue 3 - 202I

\author{
Maya Dewi Dyah Maharani,' June Mellawati \\ 'Environmental Engineering Department, Sahid University, \\ Indonesia \\ ${ }^{2}$ National Nuclear Energy Agency, Center for Safety Technology \\ and Radiation Metrology, Indonesia
}

\begin{abstract}
Correspondence: Maya Dewi Dyah Maharani, Environmental Engineering Department, Sahid University, Prof. Dr. Supomo, SH Streets. No. 84 Tebet, Jakarta Selatan I 287, Indonesia,
\end{abstract} Emailmayasudarsono@gmail.com,maya@usahid.ac.id

Received: April 12, 202I | Published: May 27, 202 I

Keywords: governance, nuclear, safety, security

\section{Introduction}

Nuclear technology is an important means to support national development programs in Indonesia, especially in the areas of health, food, and agriculture, water resource management, and environmental protection. Indonesia's seriousness in the field of nuclear technology has been demonstrated through the MoU signed by the head of the Ministry of Defense Research and Development Agency, Dr Anne Kusmayati, and ThorCon International Chief Representative Bob S. Effendi. According to ThorCon's statement, the project expects to make significant progress by 2025 . The proposed reactor is, however, much smaller than the fully commercial $500 \mathrm{MW}$ nuclear power plant thorcon has designed over the past five years and which is a major design goal.

Nevertheless, on the other hand, the problem of nuclear safety and security is still an important issue for the international and national world considering the risk if nuclear materials fall into the hands of irresponsible people and even used for damage. ${ }^{1}$ Therefore, it is necessary to protect the facilities and the nuclear material.

In its execution, safety and security management system is intended to:

(i) Increase the effectiveness of safety, security and health protection in a planned, scalable, structured and integrated manner

(ii) Prevent and To reduce accident events involving management elements and all employees. As an institution that manages nuclear facilities, it certainly has a certified management system.

There are 5 main requirements, for institutions that manage nuclear facilities, namely

\section{(i) Safety}

(ii) Security

(iii) Health

(iv) Orderly administration, and

(v) The quality of the product, so that it must have a management system Certified and recognized by a certification body with a reputable national/international management System).

To meet the 4.0 industrial era that focuses on the technological advancement of the present, nuclear technology for the peaceful purpose by promoting safety and safety of workers and the public and its environment becomes necessary to be studied. Especially that the use of nuclear technology in Indonesia has penetrated in various fields and to various regions in Indonesia so that the governance becomes very important in relation to about safety and security. Based on this research purpose is to formulate the governance of security and safety program of the use of nuclear technology in Indonesia by understanding the interaction and contextual relationships of three elements and identifying elements that have thrust (power driver) High and low dependence.

As one of the countries that have signed a joint convention, the safety of residual nuclear fuel Management and the safety of radioactive waste safety management, nuclear security conventions and the Physical Protection of radioactive materials should have been is being required to implement a very high occupational safety culture. ${ }^{1}$ According to this, the users of nuclear technology should also implement a high safety culture.

Human factors as well as security culture, are important factors in ensuring the safety and safety of the facilities, infrastructure 
and transportation of nuclear materials. For example, BATAN has been operating a nuclear reactor since 55 years ago always follow international regulations and standards. ${ }^{1}$ BATAN also supports the National Energy Sovereignty program in terms of managing radioactive minerals that cooperate with the private (PT. Timah). Energy sovereignty is the right of a nation and nation to independently determine energy management policies to achieve resilience and energy independence. ${ }^{2}$

\section{Subject matter}

\section{Governance}

Governance is a combination of processes and structures implemented by the Board to inform, direct, manage, and monitor organizational activities to achieve the objectives. Governance encompasses everything related to action or behavior that is directing, controlling, affecting public affairs to realize those values in daily life.

\section{Interpretive structural modeling}

Interpretive Structural Modeling (ISM) is a modeling technique developed for strategic policy planning..$^{3-5}$ As a descriptive modeling technique, ISM is also a structuring tool for a direct relationship. ${ }^{6}$ The ISM is a sophisticated planning methodology used to identify and conclude a wide variety of relationships between factors in a particular problem or issue. ${ }^{7}$

The basis of decision making in ISM technique is the group. The resulting structural model is intended to photograph complex problems of a system through carefully designed patterns using graphics and sentences. The ISM technique is able to transform a mental model that is unclear to be a visible system model.

An interpretive structural model (ISM) is presented with elements classified using Matriced the impact of the thrust of Applique'e a UN Classement (MICMAC). ${ }^{5,8,9}$ ISM can assist in the maintenance management of elements interactions that affect the probability of human failure in the use of nuclear technology, and help management design policies and guidelines for safety and security using nuclear technology.

According to Saxena (1992), It is stated that the ISM technique provides a base analysis program where the information produced is very useful in policy formulation as well as strategic planning. ${ }^{10}$ The concept of Saxena (1992), the program is grouped into nine elements, namely:

1) The affected community sector

2) The needs of the program

3) Program objectives

4) Possible changes

5) Major constraints

6) Benchmarks to assess each objective

7) Activities required for action planning

8) Measures of activity to evaluate the results achieved by each activity

9) Institutions involved in the implementation of the program. ${ }^{10}$

Referring to the concept, the formulation of policies and effective programs that support "the governance of nuclear technology safety and security in Indonesia" in this study prioritizes three elements, namely a) The objectives of the program

b) Constraints

c) Of the institution involved in the program.

The three things that the ISM method generates include:

i. The key element

ii. The structure of the element hierarchy

iii. The grouping of elements in four classification sectors.

The four sectors of the classification are sector I or independent, sector II or linkage, sector III or dependent, and sector IV or autonomous. The independent sector classification is an element that has high thrust power and low dependence. The linkage sector classification is a sector that has an unstable inter-change relationship and any change in action from the amendment will have an impact on the other sub-elements. The feedback of its influence can enlarge the impact so that these sub-elements should be carefully examined. Classification of dependent sectors is non-free sub-elements. The Autonomous sector classification is a sub-element that has little relation but can affect the achievement of the objectives.

\section{Methodology}

This study was conducted from November 2018 - April 2019. In this research, data collection and information are conducted, as well as the achievement of the performance components of the objectives, constraints and institutions related to the safety and security governance of nuclear technology, which is subsequently used as Generating tool. ${ }^{5}$ The data processing methods used are Interpretive Structural Modeling (ISM) through an expert survey in-depth interview of various cross-disciplinary experts to acquire elements and sub-elements or Brainwriting or Clinical interviews in. ${ }^{2}$ Data is derived from the study of literature, and the opinion of experts in the fields of nuclear, social and persistent technology. An expert of 7 people consisting of academics, bureaucrats and private elements.

\section{Results and discussion}

Based on the literature, expert opinion, and practitioners, as well as observation of the perception of the safety and security governance of nuclear technology, identified sub-elements of the three elements (Table 1).

Table I Contextual relationships between structural model elements

\begin{tabular}{lll}
\hline No. & Element & Contextual relations \\
\hline $\mathrm{I}$ & The purpose & $\mathrm{G}^{\mathrm{i}}$ Role support $\mathrm{G}^{\mathrm{i}}$ \\
2 & Main obstacles & $\mathrm{K}^{\mathrm{i} \text { Causes } \mathrm{K}^{\mathrm{i}}}$ \\
3 & The institution involved & $\mathrm{L}^{\mathrm{i}}$ his role supports $\mathrm{L}^{\mathrm{i}}$
\end{tabular}

\section{Sub-elements of program objective}

The destination element consists of ten sub-elements, namely:

(i) Pressing possible the event of a Nuclear Accident (G1)

(ii) Nuclear technology for water resource Management (G2)

(iii) Reducing the negative impact of the utilization of nuclear technology (G3)

(iv) Increasing legal awareness of nuclear technology (G4)

(v) Guaranteeing the discipline of nuclear technology (G5) 
(vi) The People's Welfare (G6), (vii) Ensuring safety in facilities, infrastructure, and transportation of nuclear materials (G7)

(vii) Support National Development in Health (G8)

(viii) Supports national development in food and agricultural preservation (G9)

(ix) Ensure the safety of workers, community members and the Environment of nuclear Technology (G10). ${ }^{11}$

An expert assessment of the contextual relationship between subelements of the goal resulted in a respondent's perceptual perception called the Structural Self Interaction Matrix (SSIM). Furthermore, a revision of SSIM with the rules of transitivity to the resulting final matric reachability matrix, as well as can be determined the level of dependency and the power driver of the destination element. The results of the consistency of expert opinion of $>80$ percent, meaning that the perception of expert opinion can be judged well so it is acceptable.

The contextual relationship between the objective sub-elements demonstrates the role of supporting the program. The results of the ISM's processing show that nuclear technology to ensure worker safety, community members and environmental/users of nuclear technology (G10) has high diver power and low dependence. The understanding of nuclear safety and security has the same fundamental objectives for the protection of workers, communities and the environment from radiation hazards. ${ }^{12}$

Like Indonesia who is considering a nuclear power program will be faced with many challenges to convince security guarantees, such as those experienced by other countries that started the program. ${ }^{13}$ This goal Sub-element plays a very supportive purpose in the program. Therefore, these sub-elements are the key sub-elements of the program's objective element.

Based on the sub-element objective classifications seen in Figure 1 , it is identified that the G10 key sub-element is the objective subelement that has a high driver power to the program's success (Figure 1). These Sub-elements have little reliance on the program, so the program failure does not directly impact.

In Figure 1 It is shown that the sub-elements included in the linkage sector, namely: suppress possible occurrence of nuclear accident (G1), Nuclear technology for water resource management (G2), Increase awareness of legal utilization of nuclear technology (G4), guaranteeing the discipline of nuclear technology (G5), the welfare of the people, (G6), supports national development in the field of health (G8). The classification analysis also shows the sub-elements included in the dependent sector: supporting national development in Food and agriculture (G9), ensuring the safety in facilities, infrastructure and nuclear material transportation (G7), mitigating negative effects of nuclear technology utilization (G3).

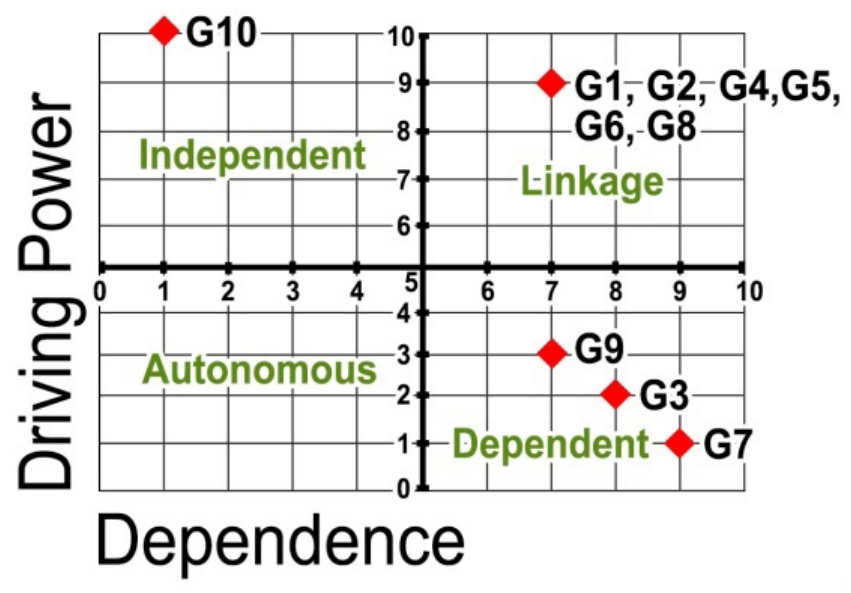

Figure I Relationship between driver power and dependency on the object element.

Description:

GI: Suppress possible occurrence nuclear accident,

G2: Nuclear technology for water resource management,

G3: Mitigating the negative effects of nuclear technology,

G4: Increase awareness of legal utilization nuclear technology,

G5: Guaranteeing the discipline of nuclear technology,

G6:The welfare of the people,

G7: Ensuring the safety in facilities, infrastructure and nuclear material transportation,

G8: Supports national development in the field Health,

G9: Supporting national development in the field Preservation of food and agriculture,

GI0: Ensure the safety of workers, community members and the environment of nuclear technology.

\section{Sub-element constraints}

The constraints element consists of ten sub-elements, namely:

i. The lack of experienced nuclear human resources in various fields, and the weak implementation of occupational safety culture (K1) ii. Have not in common the implementation of nuclear technology in the general public through formal and non-formal education (K2)

iii. Unoptimal implementation of the standard guidelines of safety and security procedures operations, and implementation guidelines Recurring/Periodic inspection (K3) 
iv. The absence of sanctions and lack of awareness regarding the discipline of nuclear technology (K4)

v. Lack of harmonizing of the interests of the Community with the established nuclear safety rules and the legal system (K5)

vi. There are not many radiation monitoring equipment available in several strategic facilities in Indonesia (K6)

vii. Lack of data, information as evidence that the use of nuclear technology capable of the people (K7) viii. Strengthening security surveillance and nuclear regard is still weak $(\mathrm{K} 8)$

ix. Still limited utilization of technology Among farmers (e.g. mutant seeds), as well as private communities (e.g. food preservation technology) (K9)

$\mathrm{x}$. The unfinished preparation of the Water Resources Act (K10), ${ }^{14,15}$ shown in Figure 2.

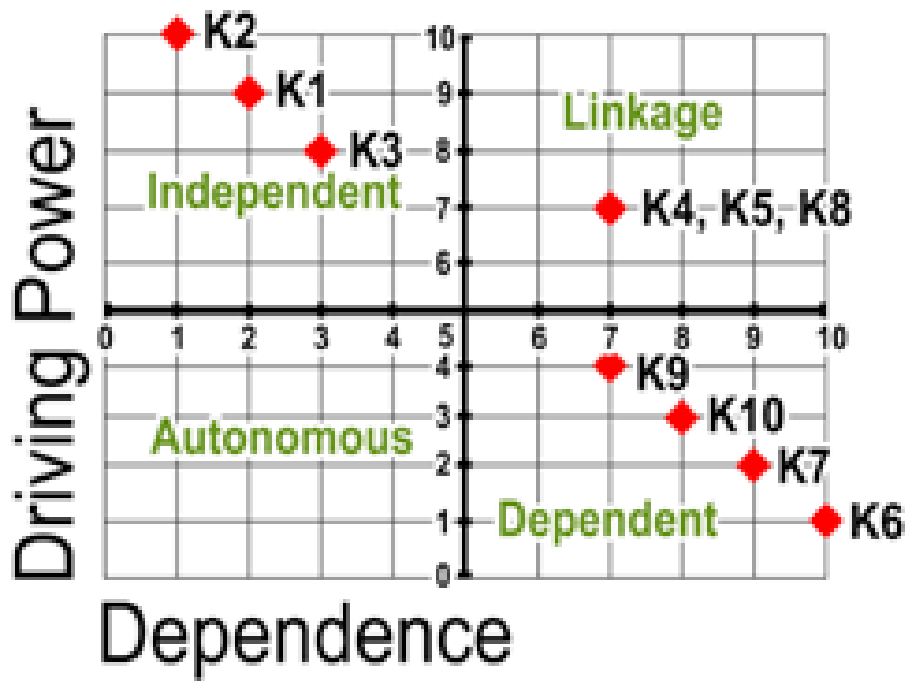

Figure 2 Relationship of driver power -dependence in constraint elements.

\section{Description:}

$\mathrm{KI}$ :The number of experienced nuclear human resources in various areas is still minimal and the implementation of occupational safety culture is still weak,

$\mathrm{K} 2$ : Dissemination of nuclear technology in the general public through formal and non-formal education is not yet equitable,

K3: Implementation of standard guidelines of safety and security procedures operations, as well as the guidelines for implementing recurring/periodic inspections, is not optimal,

$\mathrm{K} 4$ :Awareness related to the discipline of nuclear technology is still lacking and no sanction,

$\mathrm{K} 5$ :The interest of the community by the rules of nuclear safety and the legal system is less harmonious,

K6: Radiation monitoring equipment in various strategic facilities in Indonesia is not widely available,

K7: Data, information, and evidence of the use of nuclear technology that can afford the people is still minimal,

K8: Strengthening security surveillance and nuclear regard is still weak,

K9:The use of nuclear technology among farmers (various mutant seeds) and private (food preservation technology) is still limited,

K I0:The Water Resources Act has not been completed.

The assessment of the expert opinion on the contextual relationship between the sub-elements of constraints forms a perceptual perception of respondents called the Structural Self Interaction Matrix (SSIM) matrix. Furthermore, a revision of SSIM with the rules of transitivity to the resulting final matric reachability matrix, as well as can be determined by the level of dependency and the power driver of the destination element. The results of the consistency of expert opinion of $>80$ percent, meaning that perceptions of expert opinion can be assessed well.

Following the contextual relationships on these elements, the results of the ISM show that it has not been in fact dissemination of the adoption of nuclear technology in the general public through formal and in-formal education (K2). It looks like the K2 sub-elements have a high driving force and a low dependency, so those sub-elements are a key sub-element of the constraint element. The Sub-element of the constraints of the lack of experienced nuclear human resources in various fields, and the weak implementation of occupational safety culture (K1), not the optimal implementation of standards of safety and security procedures Operating guidelines (SOP), as well as guidelines Implementation of repeated/ periodic inspections (K3) including the independent sector, namely having high thrust and low dependence (Figure 2). Not optimal implementation of security and safety SOP guidelines is related to the concept of dose constraints, which until now is still a debate. ${ }^{16}$

The absence of sanctions and lack of awareness related to the discipline of nuclear technology (K4), lacking harmonicity of the interests of the community with the rules of nuclear safety made and the legal system (K5), and still weak strengthening supervision Security safety and nuclear Seifgard (K8) are included in the linkage sector. The three obstacles (K4, K5, and K8) need to get special attention because they are unstable constraints. Every action on the obstacle will impact and influence the feedback can increase its impact on other constraints (Figure 2). 
The use of nuclear technology among farmers (various mutant seeds) and private (food preservation technology) is still limited, (K9), The Water Resources Act has not been completed (K10), data, information, and evidence of the use of nuclear technology that can afford the people is still minimal (K7) and radiation monitoring equipment in various strategic facilities in Indonesia is not widely available (K6) including in the dependent sector, and is a result of the actions undertaken by the constraints of linkage and independent sectors (Figure 2)

\section{Sub-elements of institutions involved}

Elements of the involved institutions consist of ten sub-elements, namely:

a) BAPETEN (L1)

b) BATAN (L2)

c) BNPB (National Disaster Management Agency) (L3)

d) Central government (Central Hospital with radiation disaster section) (L4)

e) R \&amp; D Nuclear technology Utilization (Ministry of Health, Ministry of Agriculture, etc.) (L5)

f) Private company (Irradiator services Industry (PT Rel-Ion Sterilization Services) (L6) g) Local government (State and Private Hospital that with radiation disaster section) (L7)

h) Indonesian Nuclear Profession Association L8)

i) Youth community National Nuclear (L9)

j) State University and or Private University that has a nuclear studies program (L10).

The 10 sub-elements identified relationship or association through an expert opinion survey with the ISM method.

The analysis results show that the institution that has a role in supporting the program is the National Nuclear Energy Agency (BATAN) (L2). This sub-element has a high driving force and a low dependency compared to other sub-elements, so the sub-elements are key sub-elements (Figure 3). BATAN as a key institution is responsible for safety, security, and nuclear safeguards so that it must continue to develop physical and digital technology. The digital products of the nuclear technology currently owned by BATAN are for non-destructive tests, namely Computed Tomography (CT) and Digital Radiography (DR) which offer several advantages over previous technology that is still conventional. ${ }^{17}$ These advantages include faster, more accurate/ precise, high sensitivity, and economically competitive (cheap) both hardware and software.



Figure 3 Power-dependence driver relationships on institutional elements.

Description:

LI: BAPETEN (nuclear energy Supervisory Agency),

L2: BATAN (National Nuclear Energy Agency),

L3: BNPB (National Management Agency Disaster),

L4: Central government (Central hospital, section of the radiation disaster),

L5: R \&amp; D nuclear technology User (Ministry of Health, Ministry and agriculture, etc.),

L6: Private company (Iradiator services Industry (PT Rel-Ion Sterilization Services),

L7: Local Government (local hospital, \& Private: Section of the radiation disaster),

L8:Association of Nuclear Profession Societies of Indonesia (PPNI),

L9:Young National Nuclear community,

LI0: State University and or Private University that has a nuclear studies Program.

Based on the level of dependency and force driver, sub-element of the National Nuclear Energy Agency (BATAN) (L2), BAPETEN
(L1), the central government (central hospital that handles radiation disaster) (L4), and local government (State Hospital and Private 
areas) (L7) is in the independent sector. ${ }^{18-20}$ The 4 (four) sub-elements are (L1, L2, L4, and L7) as free repulsion that has great driving force and affect the success of the program.

The classification analysis of the institutional sub-elements also demonstrates the absence of free and affected the existence of the program as a result of the action of the Peubah of other sub-elements. Sub-Elements belonging to non-free variables are the National Nuclear Youth Community (L9), the State University and or private universities that have a nuclear studies Program (L10), private companies (Iradiator service Industry) (PT Rel-Ion Sterilization Services) (L6), and research on nuclear technology (Ministry of Health, Ministry of Agriculture, etc.) L5 (Fig. 3). The Association of Nuclear Society of Indonesia (L8) and the Institute of BNPB (National Disaster Management Agency) (L3) is classified in the autonomus sector, namely institutions that still have little relation but can affect the achievement of objectives ( Fig. 3). However in the future, it can be transformed into a major effect on achieving the objectives of the safety and security utilization of nuclear power, when the key objectives are successfully achieved and key constraints can be overcome.

\section{Conclusion}

The governance of the safety and security programs of the utilization of nuclear technology in Indonesia acquired through ISM analysis covering key purpose elements is the guarantee of worker safety, community members, and the environment. As a key constraint element is the weakness in the implementation of occupational safety culture and has not been in fact dissemination of the implementation of nuclear technology in the general public (public). A key institutional element involved in the implementation of safety and security governance of nuclear technology is BATAN (National Nuclear Energy Agency). The institutional Linkage classification for now, is not found, it shows that the institutions that handle the safety and security governance of nuclear technology have been stably integrated.

\section{Acknowledgments}

None.

\section{Funding}

None.

\section{Conflicts of interest}

The authors declare that there is no conflict of interest.

\section{References}

1. BATAN. Security and safety. Diakses Mei; 2019.

2. Eriyatno. System science to improve the quality and effectiveness of management. Liesa Larasati, Guna Widya, Surabaya; 2012:134:138.

3. Anonim. Final report of the Working Group of Analysis and legal evaluation in the framework of energy sovereignty. Center for Analysis and Evaluation of National Law of National Law Development Agency Ministry of Law and Human Rights of Republic Indonesia. Jakarta; 2016.

4. Aam Slamet Rusydiana. Aplication of interpretive structural modeling for cash waqf development strategy in Indonesia. Journal of Economics and Islamic Business. 2018:4(1)1-17.
5. Dyah Maharani MD, Eriyatno S, Pribadi ES. Structural model for sustainable management of ruminant catle slaughterhouse (RC-S): the establishement and renovation of RC-S. Jurnal Global Veterinaria. 2015;14(5)707-719.

6. Saptoriantoro P, John Haluan M. Planning strategy of management information system data processing fishing surveillance implementation in ministry of marine affairs and fisheries republic of Indonesia. Marine Fisheries. 2017;8(2)149-162.

7. Sage AP. Interpretive structural modeling: methodology for large-scale system. New York, NY: McGraw-Hill; 1977:91-164.

8. Sarbjeet Singh. SM-based analysis for modelling factors in railway maintenance task. International Journal in IT and Engineering. 2015;(3):279-287.

9. Dewangan DK, Rajat A, Vinay S. Enablers for competitiveness of Indian manufacturing sector: An ISM-fuzzy MICMAC analysis. Proceedings of XVIII Annual International Conference of the Society of Operations Management (SOM-14). 2015;(189):416-432.

10. Saxena JJP, Sushil Vrat P. Hierarchy and classification of program plan elements using interpretive structural modelling. System Practice. 1992;5(6):651-570.

11. Heni Y, Pandi L, Dewanto P, et al. Evaluation of the implementation of nuclear plant safety culture. Proceeding PPI-PDIPTN, Certer for Accelerator Technology and Materials Process, BATAN, Yogyakarta. 2006:110-117.

12. Sonal G, Jungmin K. Nuclear safety and nuclear security synergy. Annals of Nuclear Energy. 2013;60:357-361.

13. Laurence G Williams. Nuclear safety and nuclear security regulatory challenges facing a country embarking on a nuclear power programme. The Journal of world Energy Law \& Business. 2019;12(1)69-88.

14. Putero SH, Rosita W, Sihana F, et al. the challenges and opportunities in developing nuclear engineering education in Indonesia after Fukushima accident. Proceedings of the $2013{ }^{21}$ st International Conference on Nuclear Engineering ICONE21 July 29-August 2, 2013. China: Chengdu; 2013.

15. Suhaemi T, Sudirman N. Community participation in the development of nuclear power plants in Indonesia. Proceeding of National Seminar on Science education. 2014:1-10.

16. Kong TT, Akabani G, Poston JW. A study of a dose constraint for members of the public living around NPP in the United States. Journal Nuclear Tcehnology. 2019;205(6):781-789.

17. Donald Firesmith. Engineering safety requirements, safety constraints and safety-critical requirements. Journal of Object Technology. 2004;3(3):2742.

18. Bomanji JB, Novruzov F, Vinjamuri S. Radiation accidents and their management: Emphasis on the role of nuclear. Medicine Professionals. Nuclear Medicine Communication. 2014;35(10):995-1002.

19. Davari F, Zahed A. A management plan for hospital and medical centers facing radiation incidents. Journal of Research in Medical Science. 2015;20(9):871-878.

20. Veenema TG, Lavin RP, Bender A, et al. National nurse readiness for radiation emergencies and nuclear events: A systematic review of the literature. Nurs Outlook. 2019;67(1):54-88. 